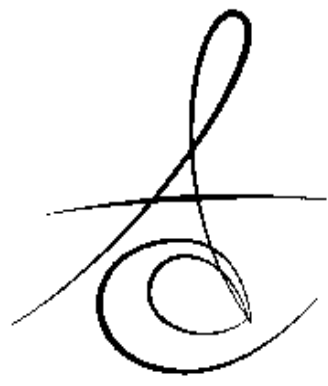

\section{DİŞ HEKİMLİĞİ RESTORATİF UYGULAMALARINDA YENİ MATERYAL OLARAK CAM KARBOMER SİMANLAR}

\author{
GLASS CARBOMER CEMENTS AS A NEW MATERIAL IN RESTORATIVE \\ DENTISTRY PRACTICE
}

Prof. Dr. Çoruh Türksel DÜLGERGİL* Arş. Gör.Dt. Ayşe Tuğba ERTÜRK*

Makale Kodu/Article code: 2638

Makale Gönderilme tarihi: 23.02.2016

Kabul Tarihi: 05.05.2016

öz

Özellikle son 20 yll içerisinde, mükemmel restoratif dolgu materyali için arayışlar hızla devam etmektedir. Kompozitlerdeki sınırsız doldurucu reaksiyonları, kompozitin rezin içeriğindeki vazgeçilmez büzülme fenomenini etkileyememektedir. Bu sebeple, cam iyonomerlere olan özlem, modifiye materyallerin oluşturulmasıyla sağlanmaya çalışılmaktadır.

Bununla beraber, cam iyonomerlerin önlenemeyen renk uyumsuzluğu, dirençlerinin ve bağlanma-ikincil çürük önleme özelliklerinin artırımasıyla telafi edilmeye çalışıııştır.

Cam iyonomerler, mine ve dentine kimyasal bağlanmaları, devam eden flor salınımı ve klinik koşullar altında büzülme göstermemeleriyle bilinirler. Düşük seviyedeki mekanik özellikler, konvansiyonel cam iyonomer simanları yüksek stress taşıyan alanlarda kullanımlarını elverişsiz hale getirmiştir. Materyalin direnç arayışı, yeni formülasyonlar ve sertleştirme tekniklerini de beraberinde getirmeye başlamıştır. Son yıllarda piyasaya sürülmeye başlanan cam karbomer simanlar bu arayışın zorunlu bir sonucu olarak ortaya çıkmaktadır. Karbomer ve floroapatitle güçlendirilmiş materyalin orta ve uzun dönemde ümit vaat edeceği açıktır.

Anahtar Kelimeler: Cam karbomer siman, cam iyonomer siman, karbomer, floroapatiti

\section{ABSTRACT}

For recent 20 years there has been a big effort to find a perfect restorative material. The particul-filler-reac tions within the contemporary composite technology could never totally eliminate the indispansible shrinkage problem of composites developed. For this reason the demand for glass ionomer materials try to cover for with producing new modified materials instead of composites. On the other hand, it has been tried to compansate of the color mismatch and solubility of glass ionomers via the increasing of the properties of chemical bonding and strength of the materials. The glass ionomer materials are known as having the specific properties including chemically bonding to enamel and dentin, continuing release fluoride, and non-contruction at clinical conditions. Due to their low physical properties glass ionomers are not suitable for high stress area. By the way, to find the new strenghtened materials, it has been started to study for new formulations and curing techniques. Recently, the new materials -glass carbomers- has been evoked due to this demand. It is clear that the material strengthed by fluoroapatite and carbomer will be so hopefull for a long time.

Keywords: glass carbomer cement, glass ionomer cement, carbomer, floropatit

\section{CAM KARBOMER SİMANLARLA İLGİLi GENEL ÖZELLİKLER:}

Karbomer ve floroapatit ile güçlendirilmiş cam iyonomer restoratif simanlardır. Çözünürlük, basınç, esneme kuvveti ve yüksek aşınma direncinin azaltılması amacıyla, özel tasarlanmış karbomer doldurucu ve floroapatit/hidroksiapatit nanopartikül içeren cam iyonomer restoratif materyaldir. ${ }^{1}$

* Kırıkkale Üniversitesi Diş Hekimliği Fakültesi Restoratif Diş Tedavisi AD 
Cam karbomer simanlar; rezin, solvent, metal vb. serbest monomer içermezler. Mine ya da dentine etching uygulaması kontendikedir. Radyoopaklığı sebebiyle postoperatif diagnozu kolaydır. ${ }^{2}$

Yüksek enerji lambalarıla polimerize edilmesi bu materyale yüksek mekanik özellikler sağlayarak üstün karakteristik özellikler sağlamaktadır. ${ }^{3}$

Olegario ve ark. ${ }^{4} 2015$ yılında yaptıkları çalışmalarında; sağlam ve enfekte dentin üzerinde cam karbomer ve yüksek vizkositede cam iyonomer simanın knoop sertlik testi ve makaslama kuvvetleri karşılaştırmışlardır. Yapılan çalışmanın sonucuna göre cam iyonomer simanın bağlanma dayanımı, cam karbomere göre daha yüksektir. Ayrıca knoop sertlik (hardness) testleri kıyaslandığında cam iyonomer, cam karbomere göre daha yüksek sertlik göstermiştir.

Çehreli ve ark. ${ }^{5} 2013$ yılında yaptıkları çalışmada ise cam karbomer simanın, cam iyonomer simana göre daha fazla mikrosızıntı sergiledikleri ve yüzeylerinde daha çok derin ve yüzeyel çatlak varlığı sergiledikleri görülmüştür.

Endikasyonları; geleneksel cam iyonomer ve kompozitlere benzer şekilde dizayn edilmiştir.

- Daimi dişlerdeki class 1 ve class 2 minimal restorasyonlarda ${ }^{1}$

- Süt dişlerindeki class 1 ve class 2 restorasyonlarda ${ }^{5}$

- Fissür örtücü olarak ya da koruyucu rezin restorasyon olarak endikedir ${ }^{6}$

Kontrendikasyon olarak; cam karbomer simanlar ile direk pulpa kuafajı yapılmaması gerektiğini ifade edilmektedir. Derin alanlarda ve pulpanın açığa çıkabileceği durumlarda kavite örtücüleri ile birlikte kullanılmalıdır ${ }^{3}$.

\section{NEDEN BU MATERYALE İHTIYYAÇ DUYULMUŞTUR?}

Cam iyonomerler; astar materyali olarak, yapıştırma, örtücü ve dişi restore etme amacıyla kullanılan esas restoratif materyaldir. Cam iyonomerler, mine ve dentine kimyasal bağlanabilmekte, sürekli flor salabilmekte ve klinik koşullar altında büzülme gösterebilmekteler ${ }^{7}$. Cam iyonomerler ile ilgili bilinen en olumsuz özellikler: Sertleşmenin başlangıç aşamalarında fiziksel direncin eksik olması, yavaş sertleşme reaksiyonu, nem hassasiyeti ve renk uyumunun olmamasıdır$^{8}$. Tüm restoratif materyallerin fiziksel, kimyasal ve mekanik özelliklerini etkileyen su emilimi, cam iyonomerlerde de tamamen kontrol altına alınamayan ve restoratif materyallerin klinik başarısını etkileyen faktörlerden biridir. ${ }^{9}$.

Düşük seviyedeki mekanik özellikler, konvansiyonel cam iyonomer simanları yüksek stress altındaki alanlarda (posterior bölgeler gibi) kullanımlarını elverişsiz hale getirmiştir. ${ }^{10}$ Cam iyonomer restorasyonlarda birkaç yıl sonra gözlenen başarısızlığın genel sebebi; erken su emilimi-erken çözünme, yorgunluğa bağlı kırılmalar ve kenar açılmalarıdır. ${ }^{11}$

Son 20 yıl içerisinde, mükemmel restoratif dolgu materyali için arayışlar hızla devam etmektedir. Çoğunluğu kompozit rezinler üzerine odaklanan çalışmalarda; kompozitlerdeki doldurucu boyut değişiklikleri ve rezin matriks içerisine katılan farklı monomer yapıları, kompozitlerdeki vazgeçilmez "büzülme fenomenini" etkileyememektedir. ${ }^{12}$ Bu sebeple, cam iyonomerlere duyulan ihtiyaç, modifiye materyallerin oluşturulmasına sebep olmuştur. ${ }^{13}$ Bununla beraber, cam iyonomerlerin önlenemeyen renk uyumsuzluğu, mekanik dirençlerinin ve bağlanma-ikincil çürük önleme özelliklerinin artırılmasıyla telafi edilmeye çalışılmıştır. ${ }^{14}$ Materyale, metal partiküllerinin eklenmesi (Ketac Silver), 1992 yılında rezin modifiye cam iyonomer simanların bulunması (VITREMER) ve son dönemlerde doldurucu boyutları azaltılarak vizkositelerinin arttırılması (Ketac molar, Easy Mix $)^{15}$ hep bu çabaların zorunlu sonucu olarak ortaya çıkmıştır. Son dönemlerde ortaya çıkan KARBOMER yapı da bu arayışın vazgeçilmez bir Örneğidir. ${ }^{16}$

Daha önceden belirtildiği gibi, cam iyonomer simanların avantajlarının (kimyasal bağlanma, flor Salınımı vs.) yanı sıra kullanımını kısıtlayan belirgin dezavantajları bulunmaktadır. Bunlar; düşük kırılma direnci, yüzey aşınması, yavaş sertleşme reaksiyonlarıdır. ${ }^{17}$

Üreticiler, cam karbomer yapısıyla birleşmiş nano boyutlu doldurucuların, yüksek çıkış aralığına sahip ışık gücüyle birleştirilmesiyle aşınma direnci ve basınç dayanımını geliştirdiklerini beyan etmişlerdir. Öte yandan; cam iyonomerlerin nanopartiküllerle (nanohidroksiapatit ve nanofloroapatit) birleştirilmesi mekanik davranışlarını geliştirmiş ve dentine olan bağlanma kuvvetini arttırmıştır. ${ }^{17}$

Simanların dayanıklılıkları ve uzun ömürlü olmaları kısmen de olsa mekanik özelliklerine bağlıdır. ${ }^{18}$ Uygulama esnasında mekanik özelliklerin geliştirilmesi amacıyla simanların sertleşmeleri esnasında ultrasonik ve ISı enerjisi kullanılabilir. Isı uygulaması yapılmış konvansiyonel cam iyonomerlerin sıkışma dirençlerinin, standart sertleşme reaksiyonu sergileyenlerle kıyaslan-

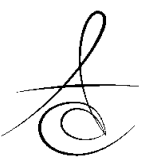


dığında erken sertleştikleri görülmüştür. Siman yüzeyinde sıcaklığın maksimum $60^{\circ} \mathrm{C}$ olacak şekilde arttırılması önemli ölçüde yüzeyde materyalin sertliğini geliştirmektedir. Ayrıca cam karbomerlere ilişkin olarak bir miktar ısının direk uygulanması simanın sertleşme kalitesiyle ilişkilidir. ${ }^{19}$

Isı uygulanmasıyla öne sürülen; cam karbomer ve konvansiyonel cam iyonomerlerin matriks oluşturma reaksiyonlarını hızlandırmaktadır. ${ }^{20}$ Farklı polimerizasyon üniteleri kullanıldığında cam karbomer örneklerinin alt ve üst yüzeylerin mikro sertlikleri arasında belirgin bir fark ölçülmemiştir ${ }^{21}$ Cam karbomer, hızlı sertleşen konvansiyonel cam iyonomerlere göre düşük mikrosızıntı değerleri göstermişlerdir. ${ }^{22}$ Bunun yanı sıra; cam karbomer simanların esneme dayanımları, konvansiyonel cam iyonomer simanlara göre daha yüksektir. ${ }^{23}$ Cam karbomer simanların makaslama kuvveti, konvansiyonel cam iyonomer simanlara göre anlamlı ölçüde daha yüksektir. ${ }^{20}$ Bu yüzden; cam karbomer simanlar büyük bir gelişme sayılabilir ve mekanik özelliklerinin doğrulanabilmesi için yeni çalışmalara ihtiyaç vardır.

\section{MATERYALIN UYGULAMA BASAMAKLARI?}

Cam karbomer, elle kolayca aktive edilebilen bir kapsül formundadır ve karıştırılması, dakikada yaklaşık olarak 4300 salınım yapan yüksek frekanslı kapsül karıştırıcı sayesinde gerçekleştirilir. $^{3}$

Uygulanacak yüzeye herhangi bir ön muamele yapılmaz ve yüzeyin kuru olması önerilir. 15 saniyelik karıştırma süresi sonunda maksimum 15 saniye içerisinde de preparasyon yüzeyine karışımın direk olarak uygulanması gerekmektedir .3

Firma önerisine göre en iyi sonuç; sertleşme sürecinde çıkış gücü $1400 \mathrm{mw} / \mathrm{cm}^{2}$ olan ve 60-90 sn. kullanılan ışık cihazıyla başarılmaktadır (maksimum $60^{\circ}$ C veya $140^{\circ} \mathrm{F}$ ). Uzun çalışma zamanı, mine ve dentine olan adezyon kaybına yol açabilmektedir (24) Bununla beraber yapılan ışık uygulaması mekanik özellikleri önemli oranda arttırır. ${ }^{19}$ Son öneri ise, yüzeye karbonsilikon içerikli (GLOSS) koruyucu tabaka uygulanmasıdır. Bu uygulama restorasyonu kolaylıkla dış etkilere karşı korumaktadır (gloss uygulaması, cam iyonomer simanlarda nemden etkilenme olayını minimalize etmek için kullanılan bir tür bonding uygulaması olarak cam karbomerlerde yapılan bir uygulamadır). Restorasyon yüzeyindeki tüm bu koruyucu tabaka, ürünün özelliklerinin gelişmesini sağlamaktadır. ${ }^{3}$

\section{.Bitirme ve Polisaj:}

- Bitirme ve polisaj işlemleri, karıştırılmaya başlandıktan yaklaşık olarak 4 dakika sonra veya hızlı sertleşme için daha öncesinde ISI uygulaması yapıldıktan sonra başlanması önerilmektedir.

- Klinik deneyimler en iyi sonucun, elmas polisaj frezleri ve sarı lastik frezlerle başarıldığını göstermiştir. ${ }^{25}$

\section{TEKNİK ÖZELLİKLERİ:}

- Saklanma şartları; orijinal alüminyum çantasında serin ortamda $4-25^{\circ} \mathrm{C}$ de olmalıdır.

- Raf ömrü 2 yıldır.

- Kapsül karıştırma süresi yüksek frekanslı karıştırıcılarda 10-15 saniyedir.

- Karıştırma sonrası ilk sıkma süresi maksimum 15 saniyedir.

- Çalışma süresi 1:15 dakikadır.

- Net sertleşme süresi 3:30 dakikadır.

- Bitirme işlemi başlamak için uygulama sonrası minimum 4 dakikadır.

\section{ÇALIŞMALAR;}

CAM KARBOMER İLE İLGİLi BİLİMSEL

İlki 2008 yılında piyasaya çıkmış olan materyalle ilgili az sayıda klinik ve laboatuvar çalışmaları mevcuttur. . $^{1,4,5,10,26-28}$

Olegario ve ark. ${ }^{4} 2014$ yılında yaptıkları çalışmada, cam iyonomer simanın (CİS) bağlanma dayanımlarının, cam karbomer simanlara göre daha yüksek olduğunu bulmuşlardır. Ayrıca materyalin sertliği bakımından da cam karbomerin, CİS' lere göre herhangi bir avantajı olmadığı gibi yüzeylerinde daha fazla derin çatlaklar barındırabildiğini belirlemişlerdir. Mikrosızıntı açısından da, CİS' lerin daha avantajlı olduğunu belirtmişlerdir.

Koenraads ve ark. ${ }^{1}$ ise 2008 yilında yaptıkları çalışmada; travma oluşturmayan dolgu işlemi (Atraumatic Restorative Teatment-ART-) yapmak için çekilmiş 100 azı dişlerine sınıf 2 kavite açmışlar ve restorasyonları aşağıdaki gruplara göre tamamlamışlardır;

- cam karbomer

- ketac molar easymix

- 3cam karbomer ve ketac molar easymix. Araştırıcılar; tek yüzeye yapılan ART restorasyonların gerek süt gerekse daimi dişlerde yüksek viskoziteli materyal kullanılmasının restorasyon başarısını etkilediğini raporlamışlardır. Araştırıcılar, materyallerin geniş sınıf II kavitelerde kullanılmasının restorasyon direnci açısından olumsuz sonuçlar yarata-

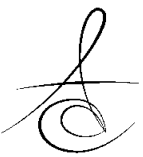


bileceğini bildirmişlerdir. Araştırıcılar çalışmalarının sonucunda; cam karbomer materyalinin dayanım açısından Ketac Easy mix ve Fuji IX a göre avantaj oluşturmadığını bildirmişlerdir.

Gorseta ve ark. ${ }^{6}$ ise yaptıkları bir klinik çalışmada, cam karbomer simanı fissür örtücü olarak uygulamışlar ve konvansiyonel rezin bazlı örtücülerle kıyaslamışlardır. Altı ve 12 hafta takip süreleri sonunda cam karbomerle yapılan tedavilerin, rezin bazlı örtücülerden belirgin ölçüde farklı olmadıklarını raporlamışlardır.

Cam karbomerlerin avantajları konvansiyonel cam iyonomerlerle kıyaslandığında önemli ölçüde daha iyi mekanik ve kimyasal özellikler sergilemeleridir. Cam iyonomerlerin sertleşme reaksiyonlarını hızlandırmak için karbo-ledlerin kullanılması, cam iyonomerlerin sıkışma dirençlerini arttırmakta ve mikrosızıntı oluşumunu azaltmaktadır. Özellikle cam karbomerlerin mineyi makaslama kuvvetinin, konvansiyonel cam iyonomer simanlarla kıyaslanabilir düzeyde olduğu hatta daha yüksek olduğu rapor edilmiştir. ${ }^{20}$

Çehreli ve ark. ${ }^{5}$ cam karbomer simanların, süt dişlerindeki mikrosızıntılarını değerlendirdikleri çalışmalarında, yüksek viskoziteli cam iyonomer simanların benzer şekilde nano-partiküllerle birleştirilmiş cam karbomer simanlar gibi aşınma direnci ve basınç dayanımı açısından iyileştirilebildiklerini ifade etmişlerdir.

Çalışmalar, dolgu yüzeyinin şekillendirilmesi sırasında yüzeyi nemlendirmek ve restorasyon yüzeyini kapatmak için "surface gloss" olarak adlandırılan karbon-silikon sıvı kullanımını önermektedirler. Yapılan çalışmalar, test gruplarında yüzey koruması yapılmadığında kenar sızdırmazlık verimliliğinin gerek konvansiyonel cam iyonomer simanlar (CIS) gerekse cam karbomer simanların her ikisinde de büyük miktarda azaldığını göstermektedir. ${ }^{5}$ (Bknz Şekil 1: A ve B)

Chan ve ark. ${ }^{26}$ Çin'de 2010 yılında kırsal alandaki 5 okulu kapsayacak şekilde yaptıkları çalışmalarında, dmft $\geq 2$ olan 407 çocuğa 4 farklı materyalle fissür örtücü yapmışlar ve 4 grup önermişlerdir; bunlar: 1cam iyonomer, 2- cam iyonomer+LED, 3- cam karbomer ve 4- rezin kompozit. İki yıl sonraki retansiyonlarını karşılaştırmışlardır. Araştırıcılar rezin kompozit örtücülerin okluzal ve pürüzsüz diş yüzeylerinde 2 yıl sonra, retansiyonlarının kısmen ya da tamamen anlamlı ölçüde diğer 3 gruba göre daha yüksek olduğunu rapor etmişlerdir. Cam karbomer örtücülerin ise okluzal ve pürüzsüz diş yüzeylerinde 2 yıl sonraki retansiyonlarının kısmen ya da tamamen diğer 3 gruba göre anlamlı derecede daha düşük olduğunu bildirmişlerdir. Yüksek viskoziteli cam iyonomer örtücülerin ISı enerjisiyle birlikte ya da enerji ilavesi olmaksızın uygulanması arasında istatistiksel olarak anlamlı bir fark bulunamamıştır.

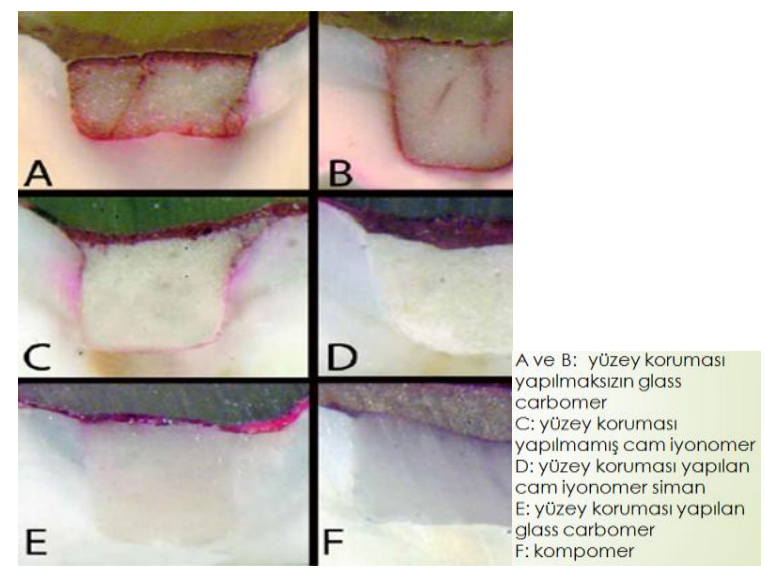

Şekil 1: Simanların mikrosızıntıları ${ }^{5}$

- 2014 yılında Zhang ve ark. ${ }^{27}$ yapmış oldukları klinik bir çalışmada ise ortalama yaşları 8 olan çocukların çürüksüz birinci azı dişlerine 4 grup şeklinde fissür örtücü uygulamışlar ve 4 grup oluşturmuşlardır. Bunlar: 1- konvansiyonel cam iyonomer, 2- ışıkla polimerize olan cam iyonomer, 3- cam karbomer, 4- komposite rezin. Altı ay, 1.yıl, 2.yıl, 3.yıl ve 4.yılların sonlarında takipleri yapılmıştır. Araştırıcılar çaIışmanın sonucuna göre; okluzaldeki pit-fissürlerde ve pürüzsüz yüzeylerde dentin çürük lezyonların prevalansının tüm örtücü gruplarında yüksek olduğunu raporlamışlardır.

- Okluzal yüzeylerdeki pit ve fissürlerde dentin çürük lezyonların, yüksek viskozitede cam iyonomerlerin ışık ile birlikte uygulandığı gruplarda, rezin kompozit gruplara göre önemli derecede daha yüksek olduğunu bildirmişlerdir. Araştırıcılar dentin çürük lezyonlarının, cam karbomer gruplarında, serbest pit ve fissürlerde kümülatif kalmaları diğer örtücü gruplarına göre istatistiksel anlamda önemli derecede daha düşük olduğu, ancak serbest pürüzsüz yüzeylerde 4 grup arasında istatistiksel anlamda önemli bir fark görülmediğini raporlamışlardır.

- Koenraads ve ark. 2009 yılında yaptıkları çalışmalarında; rezin modifiye cam iyonomer siman, cam karbomer ve konvansiyonel cam iyonomer siman ile restore edilmiş dişlerin gerilme dirençlerini ana- 
liz etmişlerdir. Araştırmacılar 3 hafta sonra restorasyonları karşılaştırdıklarında rezin modifiye cam iyonomer simanların gerilme dirençlerinin, istatistiksel olarak anlamlı ölçüde cam karbomer ve konvansiyonel cam iyonomer simanlara göre daha yüksek olduğunu raporlamışlardır. Cam karbomer restorasyonların, konvansiyonel cam iyonomer simanlara göre daha az kırığa dayanıklı oldukları sonucuna varmışlardır (Bknz şekil 2). Polimerizasyon sırasında ISI uygulanması ve gloss tabakasının ilave edilmesi simanın mekanik özelliklerini olumlu etkilediğini bildirmişlerdir.
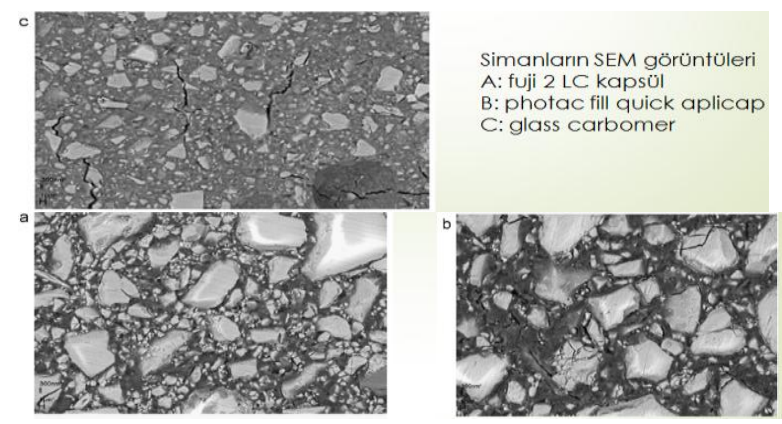

Şekil 2: Simanların sem görüntüleri ${ }^{1}$

2008 yılında Hatton ve ark. ${ }^{29}$ yapmış oldukları laboratuvar biyo-uyumluluk çalışmasında, in-vitro hücre kültürlerinden (fare fibroblastları) (L929 cells) yararlanılarak dental materyallerin biyo-uyumluluklarını karşılaştırmışlardır. Değerlendirme kriterlerine glaze, gloss ve adeziv uygulamaları da eklenmiştir. Araştırmacılar çalışmalarında; ketac molar, cam karbomer, equia, equia+glaze, ketac molar+glaze, Z100+adeziv, vitremer ve gloss gruplarından yararlanmışlardır. Sonuç olarak en iyi hücresel aktivite, ketac molar ve cam karbomer örneklerinde izlenmiştir. En düşük hücresel cevap, vitremer örneklerinden alınmıştır. Buna ilave olarak genellikle adeziv, glaze ve gloss uygulamalarının hücresel solunumu azalttığı sonucuna varmışlardır.

Chatha ve ark. ${ }^{30} 2013$ yılında yaptıkları laboratuvar çalışmasında, konvansiyonel cam iyonomer siman, cam karbomer ve rezin modifiye cam iyonomer simanların flor salma özelliklerini karşılaştırılmışlardır. Çalışmada araştırmacılar flor salma özellikleri için iyon selektif elektrodlarla (Orion Research Inc. USA) ölçüm yapmışlardır. Çalışmanın sonucu olarak bu üç materya- linde flor salma özelliğinin normal profili takip ettiği ve ilk 7 günde en üst seviyeye ulaştığı, 28-84 günleri arasında bir plato oluştuğunu rapor etmişlerdir.

Zainuddin ve ark. ${ }^{28} 2012$ yılında yaptıkları çalışmalarında; cam karbomer simanın sertleşme reaksiyonu sırasında oluşan kristal faz yapısını ve MAS-NMR (magic angle spinning nuclear magnetic resonan- ce) analizi ile $\mathrm{Al}, \mathrm{P}, \mathrm{F}$ ve $\mathrm{Si}$ iyonlarını araştırmışlardır. Araştırmacılar cam karbomer simanın içeriğindeki apatit varlığını ölçmüş, sonuç olarak cam karbomer siman içerisinde florapatit olmadığını, büyük bir kısmının hidroksiapatit olduğunu ve apatitlerin kısmen siman oluşumu sırasında azaldığını bildirmişlerdir.

\section{SONUÇ}

Materyalle ilgili umut vadeden bazı sonuçlar olsa da, materyalin klinik ömrü ile ilgili çelişkili sonuçlar mevcuttur. Nanopartikül teknolojisi ile mine benzeri yapı oluşturulmak istenmiş ve cam karbomerler ortaya çıkmıştır. Bu materyali test eden çalışma sayısı çok sınırlıdır ve cam karbomer ile yapılan fissür örtücülerde daha fazla çürük lezyonu görüldüğü bildirilmiştir.

Cam iyonomer materyallere alternatif olarak değerlendirilebilecek bu materyalin özellikle ART uygulamalarındaki uzun dönem performansının yüzey örtücü ve dolgu materyali olarak gerek süt ve gerekse daimi dişlenmede değerlendirilmesi önemli olacaktır.

Cam iyonomer simandan farklı olarak apatit kristalleriyle remineralizasyon sağladığı öne sürülen cam karbomer simanın, uzun dönem takipli klinik çalışmalarla dolguların devamlılık oranları ve remineralizasyon aktivitesinin etkinliğinin araştırılması da olumlu olabilecektir

\section{KAYNAKLAR}

1. Koenraads $\mathrm{H}$, Van Der Kroon G, Frencken J. Compressive Strength Of Two Newly Developed Glass-Ionomer Materials For Use With The Atraumatic Restorative Treatment (ART) Approach In Class II Cavities. Dental Materials. 2009; 25:551-6.

2. Algera TJ, Kleverlaan CJ, Prahl-Andersen B, Feilzer AJ. The Influence Of Environmental Conditions On The Material Properties Of Setting Glass-Ionomer Cements. Dental Materials. 2006;22:852-6. 
3. Instructions Of Use Glass Fill UK 2011 [Available From: Http://Www.Gcp-Dental.Com/Wp-Content/ Uploads/2012/08/Instructions-Of-Use-Glass-FillUK.Pdf.

4. Olegário IC, Malagrana APVFP, Kim SSH, Hesse D, Tedesco TK, Calvo AFB, Et Al. Mechanical Properties Of High-Viscosity Glass Ionomer Cement And Nanoparticle Glass Carbomer. Journal of Nanomaterials. 2015;2015:37.

5. Cehreli SB, Tirali RE, Yalcinkaya Z, Cehreli ZC. Microleakage Of Newly Developed Glass Carbomer Cement In Primary Teeth. Eur J Dent. 2013;7:1521.

6. Gorseta K, Glavina D, Borzabadi-Farahani A, Van Duinen R, Skrinjaric I, Hill R, Et Al. One-Year Clinical Evaluation Of A Glass Carbomer Fissure Sealant, A Preliminary Study. European Journal Of Prosthodontics And Restorative Dentistry. 2014;22:67-71.

7. Glasspoole EA, Erickson RL, Davidson CL. Effect Of Surface Treatments On The Bond Strength Of Glass Ionomers To Enamel. Dental Materials. 2002;18:454-62.

8. Wiegand A, Buchalla W, Attin T. Review On Fluoride-Releasing Restorative Materials-Fluoride Release And Uptake Characteristics, Antibacterial Activity And Influence On Caries Formation. Dental Materials. 2007;23:343-62.

9. SARI ME, ÖZMEN AGDB. Çocuk Diş Hekimliğinde Kullanılan Farklı Rezin Modifiye Cam Iyonomer Simanların Su Emilimi Ve Mikrosızıntı Değerlerinin Karşılaştııııması. Atatürk Üniversitesi Diş Hekimliği Fakültesi Dergisi. 2013;2013.

10. Xie D, Brantley W, Culbertson B, Wang G. Mechanical Properties And Microstructures of Glass-Ionomer Cements. Dental Materials. 2000;16:129-38.

11. Lohbauer U. Dental Glass Ionomer Cements As Permanent Filling Materials?-Properties, Limitations And Future Trends. Materials. 2009;3:76-96.

12. Barutcugil Ç, Ahmetoğlu F, Turgut H, Dayı B, Yalçın M. Düşük Polimerizasyon Büzülmesi Gösteren Modern Kompozitler Ile Metakrilat Esasli Rezin Kompozitin Konversiyon Oranlarinin Değerlendirilmesi. Atatürk Üniversitesi Diş Hekimliği Fakültesi Dergisi. 2014;24:1.
13. Yilmaz Y, Gürbüz Agdt, Eyüboğlu Agdö, Beldüz Agdn. Poliasit-Modifiye Resin (Kompomer) Ve Resin Modifiye Cam Ionomer Restoratif Materyallerin Farkli Yöntemlerle Tamirinin In Vitro Değerlendirilmesi. Atatürk Üniversitesi Diş Hekimliği Fakültesi Dergisi. 2002;2002(3).

14. Chen X, Du M, Fan M, Mulder J, Huysmans M, Frencken J. Caries-Preventive Effect Of Sealants Produced With Altered Glass-Ionomer Materials, After 2 Years. Dental Materials. 2012;28:554-60.

15. Peez R, Frank S. The Physical-Mechanical Performance Of The New Ketac ${ }^{T M}$ Molar Easymix Compared To Commercially Available Glass Ionomer Restoratives. Journal Of Dentistry. 2006;34:582-7.

16. Cho S, Cheng AC. A Review Of Glass Ionomer Restorations In The Primary Dentition. JournalCanadian Dental Association. 1999;65:491-5.

17. Cefaly DFG, Valarelli FP, Seabra Bgdm, Mondelli RFL, Navarro Mfdl. Effect Of Time On The Diametral Tensile Strength Of Resin-Modified Restorative Glass Ionomer Cements And Compomer. Braz Dent J. 2001;12:201-4.

18. Goldman AS, Chen X, Fan M, Frencken JE. Methods And Preliminary Findings of $A$ Cost-Effectiveness Study Of Glass-Ionomer-Based And Composite Resin Sealant Materials After 2 Yr. European Journal Of Oral Sciences. 2014;122:2307.

19. Menne-Happ U, Ilie N. Effect Of Gloss And Heat On The Mechanical Behaviour Of A Glass Carbomer Cement. Journal Of Dentistry. 2013;41:223-30.

20. Glavina D, Goršeta K, Vranić DN, Škrinjarić I, Editors. Enamel Shear-Bond Strength Of Glass Carbomer After Heating With Three Polymerization Units. 22nd Congress of The International Association Of Paediatric Dentistry; 2009.

21. Woolford M. Effect Of Radiant Heat On The Surface Hardness of Glass Polyalkenoate (Ionomer) Cement. Journal Of Dentistry. 1994;22:360-3.

22. Goršeta K, Glavina D, Škrinjarić I, Editors. Microleakage Of Newly Developed Nano-Ionomer And Glass Ionomer Cement Restoration. 44th Meeting Of The IADR-Continental European Division (CED); 2009.

23. Goršeta K, Vranić DN, Glavina D, Škrinjarić I,

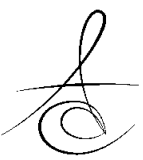


Editors. Effects Of Polymerisation Unit On The Flexural Strength Of Glass Carbomer. 22nd Congress of The International Association of Paediatric Dentistry; 2009.

24. Mandari G, Frencken J, Van'T Hof M. Six-Year Success Rates Of Occlusal Amalgam And GlassIonomer Restorations Placed Using Three Minimal Intervention Approaches. Caries Research. 2003;37:246-53.

25. Mallya PL, Acharya S, Ballal V, Ginjupalli $K$, Kundabala M, Thomas M. Profilometric Study To Compare The Effectiveness Of Various Finishing And Polishing Techniques On Different Restorative Glass Ionomer Cements. Journal of Interdisciplinary Dentistry. 2013;3:86.

26. Chen X, Du M, Fan M, Mulder J, Huysmans M-C, Frencken JE. Effectiveness Of Two New Types Of Sealants: Retention After 2 Years. Clinical Oral Investigations. 2012;16:1443-50.

27. Zhang W, Chen $X$, Fan $M-W$, Mulder J, Huysmans M-CC, Frencken JE. Do Light Cured ART Conventional High-Viscosity Glass-Ionomer Sealants Perform Better Than Resin-Composite Sealants: A 4-Year Randomized Clinical Trial. Dental Materials. 2014;30:487-92.

28. Zainuddin N, Karpukhina N, Law RV, Hill RG. Characterisation Of A Remineralising Glass Carbomer ${ }^{\circledR}$ Ionomer Cement By MAS-NMR Spectroscopy. Dental Materials. 2012;28:1051-8.

29. Http://Www.Gcp-Dental.Com/Wp-Content/ Uploads/2012/08/Studies7.Pdf2012 [

30. Chatha J H-GK, Hatton PV. Comparative Study Of Flüoride Ion Release From Direct Restorative Materials. . British Society Of Dental Research2009.

\section{Yazışma Adresi}

Araştırma Görevlisi Dt. Ayşe Tuğba ERTÜRK* Kırıkkale Üniversitesi

Diş Hekimliği Fakültesi

Restoratif Diş Tedavisi Anabilim Dalı

KIRIKKALE

e-mail: aysetugba11@gmail.com 